ISSN: 1130-3743 - e-ISSN: 2386-5660

DOI: http://dx.doi.org/10.14201/teoredu292145165

\title{
FUNDAMENTOS Y ESTRATEGIAS SOCIOEDUCATIVAS EN LA ELABORACIÓN DE LA HISTORIA DE VIDA EN EL ACOGIMIENTO EN FAMILIA EXTENSA ${ }^{1}$
}

\author{
Foundations and socio-educative strategies \\ in the elaboration of life story in kindship foster care
}

\section{Principes fondamentaux et stratégies socioéducatives dans l'élaboration de l'bistoire de vie concernant l'accueil en famille élargie}

Tania GARCÍA BERMEJO

Universidad Internacional de La Rioja (UNIR). Facultad de Educación. Departamento de Familia, Escuela y Sociedad. Avenida de la Paz, 137. 26006 Logroño (La Rioja).tania.garcia@unir.net

Fecha de recepción: enero de 2017

Fecha de aceptación: marzo de 2017

RESUMEN

El acogimiento en familia extensa es la medida de protección a la infancia más utilizada en nuestro país, que encuentra entre sus mayores dificultades la correcta elaboración de la historia de vida de los niños acogidos. Si esta construcción de la historia vital del niño, que generalmente contiene situaciones dramáticas, no se

1. Esta investigación ha sido posible gracias a la ayuda recibida en el Plan de Desarrollo del Profesorado 2016-2017 de la Universidad Internacional de La Rioja para la realización de una estancia de investigación en la Universidad de Birmingham (Reino Unido). Debo agradecer también todo el apoyo y las valiosas recomendaciones realizadas sobre este artículo a la profesora Mónica Jato. 
elabora adecuadamente, puede generar problemas identitarios susceptibles de obstaculizar un adecuado desarrollo. Este artículo analiza la narrativa como una de las principales estrategias socioeducativas para la elaboración de la historia de vida, a partir de los conceptos de experiencia fallida, experiencia imaginaria reactiva y del estadio del espejo, entre otros. Así mismo, propone la utilización de las autobiografías, el libro de vida y la literatura como herramientas para contribuir al desarrollo de la identidad del niño, el fomento de su resiliencia y el conocimiento de su historia de vida de una manera coherente y positiva.

Palabras clave: acogimiento en familia extensa; identidad; historia de vida; narrativa; experiencia fallida.

\section{SUMMARY}

Kindship foster care is the most common child protection measure in Spain, which finds the appropriate elaboration of life stories between its main difficulties. If this reconstruction of life story, which usually contains dramatic situations, is not well carried out, it could generate identity problems and hinder children's adequate development. This article analyses narratives as one of the key socio-educative strategies for the elaboration of life stories, based on the concepts of failed experience, reactive imaginative experience, and mirror stage, among others. Moreover, it proposes the use of autobiographies, lifebooks and literature as meaningful tools to foster identity development and resilience in children, in order to they may know their life stories in a coherent and positive way.

Key words: kindship foster care; identity; life story; narrative; failed experience.

\section{SOMMARIE}

L'accueil en famille élargie est la mesure de protection de l'enfance la plus utilisée dans notre pays, dont l'une des plus grandes difficultés est l'élaboration adéquate de l'histoire de vie des enfants accueillis. Si cette construction de l'histoire de vie de l'enfant, qui contient généralement des situations dramatiques, ne s'élabore pas de manière adéquate, cela peut générer des problèmes identitaires susceptibles de devenir un obstacle au développement de l'enfant. Cet article analyse la narration comme l'une des principales stratégies socioéducatives pour l'élaboration de l'histoire de vie, à partir des concepts d'expérience échouée, expérience imaginaire réactive et du stade du miroir, entre autres. Ainsi, il propose de se fonder sur l'utilisation de l'autobiographie, du livre de vie et de la littérature comme outils utiles pour contribuer au développement de l'identité de l'enfant et encourager sa résilience, afin que, de cette manière, il puisse construire son histoire de vie de manière coherente et positif.

Mots clés: accueil en famille élargie; identité; histoire de la vie; narration; expérience échouée. 


\section{INTRODUCCIÓN}

El acogimiento en familia extensa es la medida de protección de la infancia que se lleva a cabo cuando los menores se encuentran en una situación de desprotección y son los propios familiares quienes se encargan de su cuidado. Aunque es la medida de protección más utilizada en nuestro país (Del Valle, Bravo y López, 2009), priorizada por la legislación vigente frente a otras medidas (Ley Orgánica 1/1996, art. 46.2; Ley Orgánica 8/2015, art. 20.2), resulta aún desconocida tanto para el público general como para el especializado en este ámbito. Esto se debe, entre otras razones, a los escasos estudios realizados aún sobre estas familias.

En España no comienzan a publicarse trabajos sobre los acogimientos en familia extensa hasta comienzos del presente siglo. Algunos de ellos describen características generales de los acogimientos familiares, incluyendo datos sobre acogimientos en familia ajena, acogimientos en familia extensa y otras formas minoritarias de acogimientos como los de urgencia (Del Valle, Bravo y López, 2009; Jiménez Morago y Palacios, 2008; Del Valle y Bravo, 2003; Borges del Rosal, Rodríguez Naveiras y Hernández Jorge, 2013; Del Valle, López, Montserrat y Bravo, 2008). Otros, en cambio, abordan aspectos sobre los acogimientos en familia extensa, aunque también con objetivos descriptivos sin profundizar todavía en elementos clave de la intervención socioeducativa (Monstserrat, 2006, 2008; Sánchez Moro et al., 2000; Molero, Moral, Albiñana, Sabater y Sospedra, 2007; Pinazo y Ferrero, 2003; Bernedo y Fuentes, 2010). Por último, existen escasos artículos que consideren la historia de vida e identidad de los menores acogidos. Tal es el caso del psicólogo Gómez Hernández (2006), quien afirma que el 62.5\% de los menores acogidos tiene problemas derivados de las dificultades en la comprensión de su historia de vida y propone diversas claves para la intervención, pero no incide en las estrategias para hacerlo. En esta misma línea de investigación, Vis, Handegård, Holtan, Fossum y Thørnblad (2016) encuentran que los menores que residen con sus acogedores en familia extensa o en centros de protección ubicados en el mismo barrio en el que vivían con sus padres desarrollan significativamente menos problemas de salud mental que otros menores con medidas de protección familiares o residenciales que les alejan de su entorno, tanto al inicio del acogimiento como a lo largo de los años posteriores, lo que apunta a la relevancia de la continuidad en la historia vital y a la importancia del mantenimiento de los vínculos con sus elementos identitarios básicos. Balsells, Fuentes-Peláez, Mateo Gomà, Mateos Inchaurrondo y Violant Hoz (2010) concluyen en su estudio que los menores acogidos en familia extensa tienen la necesidad de conocer sus orígenes y proponen un programa de apoyo para trabajar con los acogidos con el objetivo de mejorar las necesidades detectadas en los propios menores y fomentar la resiliencia, a través de técnicas como la lluvia de ideas, la discusión dirigida, etc., pero sin utilizar explícitamente las narrativas. Más recientemente, Jiménez, Martínez, Muñoz y León (2013) publican un artículo en el que afirman que el 80.9\% de los acogedores manifiestan que es positivo hablar a los menores sobre su historia de vida, pero retrasan el momento para hacerlo o sólo lo hacen en ocasiones muy excepcionales. Por su 
parte, Jiménez Morago, Martínez Cabeza y Mata Fernández (2013), elaboran una guía para trabajar la historia de vida a través del Libro de Vida, que constituye una referencia para la intervención socioeducativa en este ámbito.

Por ello, debido a la aún escasez de estudios en esta línea de investigación, el objetivo del presente trabajo es profundizar en el concepto de narrativa como una de las principales estrategias socioeducativas que se pueden utilizar para la elaboración de la historia de vida y de la identidad en los menores acogidos en familia extensa, lo que se encuentra entre las dificultades más importantes a las que tienen que hacer frente los acogedores y los profesionales socioeducativos que trabajan con familias en esta medida de protección, tales como los educadores sociales en el ámbito de la educación no formal o los orientadores educativos desde el contexto educativo formal. Para ello, comenzaremos realizando una aproximación a los conceptos de experiencia e identidad desde la perspectiva de los menores acogidos, para posteriormente analizar las necesidades de creación de una narrativa de vida por parte de los menores con el objetivo de que la conozcan, la elaboren y la acepten, evitando así estancarse en el pasado para poder seguir viviendo su presente y mirar hacia el futuro. Finalmente, presentaremos algunas de las estrategias socioeducativas que se pueden utilizar para la correcta elaboración de la historia de vida, que incluirán las autobiografías, el libro de vida y las narraciones literarias.

\section{LA EXPERIENCIA DE LOS MENORES ACOGIDOS EN FAMILIA EXTENSA Y EL DESARROLLO DE LA IDENTIDAD}

Los menores acogidos en familia extensa han vivido generalmente situaciones graves de desprotección, tales como negligencia, maltrato físico y emocional o abuso sexual (Palacios, 2014), por lo que las administraciones públicas han propuesto y valorado para ellos una medida de protección con algún miembro de su familia. Es por ello por lo que muchos de los menores acogidos en familia extensa pueden presentar un trastorno por estrés postraumático complejo que puede afectar a la regulación de sus emociones e impulsos, a la atención y memoria, a su autoconcepto, a las relaciones que establecen con los demás, e incluso derivar en ciertas somatizaciones (López-Soler, 2008). Unido a esto, los menores acogidos que han vivido situaciones extremas en su vida pueden tener dificultades o ser incapaces de narrar su experiencia y, más concretamente, los acontecimientos negativos que han vivido. Tradicionalmente, se ha pensado que la experiencia que tienen las personas es directa e inmediata, es decir, que viven una determinada situación y automáticamente la experimentan; pero Alphen (1999) defiende que no es así, sino que la experiencia depende de cómo los sujetos la interpretan y la describen con palabras. Para este autor, los «subjets are the effect of the discursive processing of their experiences» (Alphen, 1999, 25), por lo que, para que la experiencia sea realmente vivida, la persona debe poder narrarla. Cuando los niños no ponen palabras a lo que han vivido en el pasado, su experiencia se convierte en un trauma o en lo que el autor denomina una experiencia fallida, caracterizada por la falta 
de discurso o narración de la propia viviencia, lo que conlleva que la experiencia no se haya vivido, no se haya experimentado. Es decir, si los niños acogidos en familia extensa no son capaces de poner palabras a sus acontecimientos vitales, la experiencia fallida les acompañará a lo largo de su vida a través de recuerdos involuntarios que reviven una y otra vez, pero que no entienden ni pueden explicar, lo que les impide realizar un correcto proceso de maduración. No obstante, el trauma se puede superar cuando la persona es capaz de explicar con palabras lo que vivió. Esto supone un alejamiento emocional entre el sujeto y el acontecimiento, es decir, el establecimiento de cierta distancia entre lo ocurrido y la interpretación, introduciendo en el medio de estos dos elementos el propio discurso, que permite observar lo sucedido con una perspectiva diferente, más amplia. Una vez que los niños pueden poner palabras a estas vivencias y construyen una narración congruente sobre lo que vivieron, otorgan sentido, ordenan su mente y pueden comprender y aceptar su pasado (Gonzalo, 2010).

Ahora bien, hay ocasiones en las que aunque los niños acogidos son capaces de elaborar una narrativa, ésta no sólo no refleja la realidad, sino que resulta perjudicial para los propios niños, lo que requerirá una redefinición en su elaboración. Por ejemplo, es frecuente encontrar niños que afirman que el motivo por el que no viven con sus padres se debe a que éstos están trabajando fuera de España, cuando en realidad se encuentran en prisión. Aunque estos niños han realizado una narración de su situación familiar, lo están haciendo en unos términos irreales, que les insertan en una fantasía que puede ser elaborada por ellos mismos ante la falta de información recibida sobre la situación de sus padres, o bien inducida por los acogedores, quienes, tratando de proteger a los niños de una situación dolorosa y compleja de explicar, inventan una realidad alternativa que resulta más fácilmente comunicable. En estos casos no puede hablarse de una experiencia fallida en cuanto que existe un discurso narrativo que trata de describir una situación, sino más bien de lo que podríamos llamar experiencia imaginaria reactiva. Es decir, aquella experiencia vivida cuya narración es irreal con motivo de la reacción ante un acontecimiento no deseado. Este acontecimiento no deseado puede ser la realidad conocida por los acogidos ante la cual elaboran una narrativa alternativa, o bien la ausencia de información que se desea subsanar por parte de los niños sobre un acontecimiento tan relevante para ellos como la ausencia de sus progenitores.

A consecuencia de la situación de desprotección marcada por una historia de vida complicada, los menores acogidos en familia extensa deben hacer frente a un doble reto: por un lado, tienen que rehacerse a estas situaciones de maltrato, abandono y/o negligencia, que han sufrido con anterioridad a la medida de protección, donde la resiliencia, de la que hablaremos más adelante, jugará un papel importante; y, por otro lado, tienen que conformar su identidad. Siguiendo a Coleman y Hendry (2003), la percepción que tienen los menores de sí mismos y su propia comprensión influirán significativamente en su manera de enfrentarse a determinadas situaciones de la vida. La clave para desarrollar una maduración psicológica está en dar sentido al mundo en el que se vive y sentirse seguros en él. 
De aquí la importancia de que los menores acogidos puedan narrar sus historias de vida para conseguir un desarrollo adecuado y con la suficiente seguridad para seguir avanzando. La base para que los menores puedan construir una identidad adecuada está en que sean capaces de desarrollar una narrativa de su vida (Caro, 2013), y para ello los acogedores juegan un papel muy importante, pues, según afirman los propios menores, la familia es la principal agencia para construir su identidad (Bernal Guerrero y König, 2017) y, a su vez, la identidad es una fuente de arraigo (Bernal Guerrero, 2011).

Ahora bien, también es necesario tener en cuenta aspectos emocionales como elementos importantes para el desarrollo de la identidad del niño acogido. Tajfel (1984, 292) concibe la identidad social como "aquella parte del autoconcepto de un individuo que deriva del conocimiento de su pertenencia a un grupo (o grupos) social junto con el significado valorativo y emocional asociado a dicha pertenencia». Por lo tanto, para el adecuado desarrollo de la identidad global del niño es imprescindible la relación que establece con sus cuidadores y el relato de la historia de vida del niño que se realiza, ya que el autoconcepto del menor estará infuido por el conocimiento que tenga del grupo social al que pertenece y por las emociones que esto le genere. Si los cuidadores del acogido, en el discurso sobre el propio menor, incluyen descalificativos, culpa, desinterés, etc., el autoconcepto del niño va a ser negativo, por lo que, si pensamos en la elaboración de su historia de la vida, podemos afirmar que, para un desarrollo adecuado de la identidad, los acogedores no deben incluir aspectos desmotivadores y negativos sobre el propio menor y la historia del grupo familiar.

La teoría del estadio del espejo de Lacan (2009) puede realizar aportaciones relevantes a esta cuestión. Según este autor, los niños entre los seis y los dieciocho meses empiezan a configurar su yo cuando ven su imagen proyectada en un espejo y se reconocen y perciben como personas en su conjunto, y no sólo como partes de sus cuerpos desconectadas, lo que, además, les produce un sentimiento de gran satisfacción. Para que este proceso de reconocimiento se produzca, afirma Lacan, es necesario también que en el mismo espejo se refleje, junto a la del niño, la imagen de alguna figura humana que el niño reconozca, como suele ser la de alguno de sus progenitores.

Si aplicamos esta teoría a la elaboración de la identidad en los menores acogidos en familia extensa, podemos establecer un paralelismo entre el espejo físico y la narración sobre su historia de vida. Los niños acogidos, para reconocerse como personas y elaborar su identidad de una manera adecuada, necesitan conocer su historia de vida sin saltos en el tiempo y sin lagunas, pues de esta manera tendrán más posibilidades de desarrollar una identidad completa. Si piensan en su vida y no tienen una narración coherente sobre ella, construirán su identidad de una manera inadecuada, desconectada, informe, como el niño pequeño que piensa en sí mismo como miembros de su cuerpo sin unión entre ellos. De esta manera, el efecto espejo se traslada desde el propio espejo físico como objeto hasta la narración de la historia de vida, la cual, si es coherente, reflejará una imagen completa 
del niño acogido que le permitirá conformar adecuadamente su identidad. Así mismo, como veremos más adelante, este efecto espejo también puede producirse de manera similar en las narraciones literarias, en cuyos personajes el niño se reconoce a sí mismo encontrando elementos que construyen su identidad y ayudan a la comprensión de su yo.

Por otro lado, si tenemos en cuenta que, según Lacan, es necesaria la figura de una persona conocida por el niño reflejada en el mismo espejo que él a fin de que se complete el proceso de reconocimiento, de forma similar, para la construcción de la identidad del menor acogido puede ser imprescindible la colaboración de los acogedores en un doble sentido. En primer lugar, constituirán un apoyo imprescindible en la explicación de la historia de vida, especialmente en aquellos episodios de mayor complejidad que pueden ser difícilmente comprensibles para el niño, como, por ejemplo, la muerte de uno de los padres, su ingreso en prisión, la adicción a las drogas, etc. Y en segundo lugar, la narración conjunta de la historia de vida entre los cuidadores del niño y el propio menor, en la que existe un pasado común, facilitará la formación de la identidad del niño, al ser consciente de que forma parte de la vida de los acogedores y de que, aunque no pueda residir con sus padres biológicos, está unido emocionalmente a sus acogedores a través de una historia compartida. En este sentido, los acogedores ejercerían un rol que se asemeja a lo que Cyrulnik (2003) denomina tutores de resiliencia, o personas necesarias en el desarrollo de esta capacidad en los niños, que les acompañan en los momentos más difíciles y constituyen un apoyo imprescindible para superar los posibles traumas. En este caso, los acogedores, al acompañar a los niños en esa narración vital, se convertirán en tutores de resiliencia.

De manera especial, cuando los menores llegan a la adolescencia comienzan a preguntarse ¿quiénes son?, ¿de dónde vienen?, ¿a quién se parecen? Preguntas que explícita o implícitamente necesitan contestar para conformar su identidad. Si bien las respuestas son habitualmente difíciles de encontrar incluso con un pasado claro y en una familia nuclear, la situación se torna más complicada cuando existen lagunas e incoherencias en su historia vital. Múgica (2010) afirma que si los menores no tienen claro su pasado, tendrán muchas lagunas que deberán rellenar, y tenderán a hacerlo en el mejor de los casos con fantasías y cuentos de hadas o, lo que resulta más perjudicial, con ideas negativas. Por ejemplo, ante la falta de información sobre los padres biológicos, los niños pueden pensar que los acogedores son sus padres, con los problemas que ello puede generar por la importante diferencia de edad en caso de abuelos acogedores, o los conflictos que pueden aparecer cuando por diversos motivos se producen contactos con los padres biológicos, lo que puede tener un encaje complejo en la estructura cognitivo-emocional del niño acogido. Más graves son las situaciones en las que, al intentar explicar la separación de sus progenitores, los niños se atribuyen a sí mismos la responsabilidad de dicho acontecimiento, interpretando que por su mal comportamiento merecen que no sean queridos sino abandonados. Esto genera que su identidad se construya sobre una gran mentira y se vea drásticamente dañada. De esta manera se quedan 
estancados en un pasado en el que han sufrido mucho y que no logran entender adecuadamente, lo que no les permite seguir avanzando hacia un futuro mejor. Todas estas preguntas sin contestar, o contestadas erróneamente, pueden llevarles a generar sentimientos de culpa y responsabilidad excesiva o malinterpretada. Siguiendo a Noddings (2009), el niño debe sentirse orgulloso de lo que encuentra ante la respuesta de ¿quién soy yo?, y para esto es necesario que puedan entender y aceptar su pasado.

Por ello, la intervención socioeducativa debe buscar herramientas que puedan servir tanto a los menores acogidos como a sus acogedores, a la hora de contar y entender la historia de vida, para que se realice de la manera más apropiada sin dañar a ninguna de las partes. En el estudio realizado por Jiménez, Martínez, Muñoz y León (2013), se afirma que, a pesar de que el acogimiento en familia extensa proporciona importantes ventajas para los menores, tales como sentimiento de pertenencia, vínculos afectivos familiares y relación con los hermanos, es necesario tener en cuenta las dificultades presentes en muchos de ellos como la baja formación de los acogedores y la falta de apoyo, pues todo ello repercute en las dificultades de los cuidadores para contar la historia de vida a los menores acogidos y a establecer relaciones positivas con los padres biológicos de los niños.

\section{3. ¿ES NECESARIO EL TRABAJO DE HISTORIA DE VIDA CON MENORES ACOGIDOS EN FAMILIA EXTENSA?}

\subsection{La bistoria de vida en la legislación}

Entre los principios que se establecen en la Declaración de los Derechos del Niño (1959) destaca el derecho a que se cubran sus necesidades básicas, de educación, de alimentación, de apego, etc. Ahora bien, cabe preguntarse si entre dichas necesidades no se encontraría el derecho a conocer su historia de vida para poder elaborar su identidad sobre unos cimientos sólidos. Sin duda, el hecho de que los menores mantengan una alimentación sana y equilibrada, así como una adecuada estimulación sensorial, cognitiva y afectiva, resulta fundamental para un correcto desarrollo. Sin embargo, este desarrollo puede verse truncado si el niño tiene lagunas en su historia vital y construye su identidad sobre una serie de fantasías. Por ello, dentro de las necesidades básicas que deben atenderse en la infancia, y especialmente en la infancia vulnerable, convendría incluir el conocimiento de su pasado de una manera adecuada y coherente. Posteriormente, en el artículo 8 de la Convención sobre los Derechos del Niño (1989), se pone de manifiesto que los Estados partes deben respetar el derecho del niño a preservar su identidad. Aunque tampoco se recoge explícitamente del derecho a conocer su pasado, ya se empieza a conceder importancia a la identidad, que como hemos visto anteriormente está estrechamente relacionada con el conocimiento de la historia de vida.

En la reciente Ley 8/2015, de 28 de julio, de modificación del sistema de protección a la infancia y a la adolescencia, se enfatiza la importancia del contacto 
del niño con su familia de origen -siempre preservando el bienestar superior del menor- cuando se ha tomado una medida de protección, bien sea un acogimiento familiar o residencial (vid. p. e. arts. 2 y 34). De esta manera, se evita una brecha en la historia vital del niño, manteniendo una coherencia fundamental para su adecuado crecimiento, lo cual permite la construcción de la historia del niño de una manera más natural y coherente siempre que las partes implicadas (padres y acogedores) sean conscientes de la importancia que esto comporta para el futuro del menor. Es decir, se enfatiza la necesidad de que el niño tenga integradas sus vivencias a través de las explicaciones de los adultos más significativos para él, con el objetivo de ayudarles a suturar las fisuras que puedan tener en su historia vital y a restablecer, en la medida de lo posible, una continuidad entre el pasado y el presente del menor. Para ello, resulta imprescindible que todos los adultos transmitan la misma realidad al niño sin que existan contradicciones en dichas explicaciones y sean coherentes, por lo que es fundamental tanto el diálogo entre las partes, directo o mediado, como las herramientas adecuadas para la transmisión de información al menor y la contestación a sus preguntas.

Por su parte, en el Plan Estratégico Nacional de la Infancia y Adolescencia 2013-2016, aunque no se refiere explícitamente al acogimiento familiar, se incluye una medida de actuación en el cuarto objetivo de Protección e inclusión social sobre la promoción legislativa y la elaboración de protocolos que faciliten la búsqueda de la familia de origen del niño adoptado para garantizar su derecho a una identidad filial. Esto es un paso importante para que los profesionales socioeducativos comiencen a pensar en estos términos y tengan, entre sus objetivos de intervención, la elaboración de esta historia de vida de los niños que no residen con sus padres biológicos.

\subsection{Beneficios de estar informado y consecuencias de no estarlo}

Desde Platón, sabemos que no es fácil enfrentarse a la realidad de las cosas. En la República explica su mito de la caverna, en el que se observa cómo quienes estaban en tinieblas contemplando las sombras de las figuras que pasaban detrás de ellos, sin que pudiesen darse la vuelta para mirarlas directamente, tienen la oportunidad de salir de la cueva y contemplar la realidad con sus propios ojos. Pero en los primeros momentos la luz no les deja ver completamente y necesitan un tiempo de adaptación. Durante ese tiempo, hay algunos que prefieren volver a la caverna, a la comodidad de las sombras. Otros más valientes soportan el primer deslumbramiento y llegan a contemplar la realidad. Algunos de estos vuelven a la caverna y, al contar lo que han visto, son rechazados por los otros que no creen lo que éstos les cuentan. Esta metáfora filosófica es un buen ejemplo de que conocer la realidad no es un asunto sencillo ni, en muchos casos, indoloro. Para las familias acogedoras, y en concreto para los menores acogidos, su realidad puede ser difícil de asumir y en ocasiones pueden llegar a rechazarla. Si bien es cierto que contarle a un niño pequeño que sus padres son toxicómanos o que se encuentran 
en prisión no resulta fácil, debe tenerse en cuenta que, por muy dolorosas que sean las explicaciones, es la realidad del niño y éste tiene que conocerla para ir elaborándola gradualmente. Para Aguirre, "[1]a verdad es como un desinfectante, necesario pero que escuece; a la verdad se la teme, pero es imprescindible» (1998, 79). La historia de vida en los menores acogidos es ese desinfectante que deben conocer, para cicatrizar las heridas y poder seguir avanzando sin estancarse en el pasado. Cuando el niño conoce datos verídicos de su pasado de boca de sus padres o acogedores, las lagunas de información y la desconexión en su historia tienden a desaparecer, facilitando así la aparición de una narrativa más lógica, coherente y gradual, que da sentido a su vida.

Muchos niños acogidos en familia extensa conocen parcialmente su historia ya que han recibido cierta información en un momento determinado, de manera fragmentada, directa o indirecta, pero es probable que no se volviera a hablar sobre ello por el dolor que la conversación sobre el tema genera. Por ello, los conocimientos que pueden tener los niños sobre su pasado pueden ser negativos, inconexos y sin significado o incluso convertirse en un tema tabú del que no se puede hablar con los acogedores. En consecuencia, es necesario que los acogedores traten la historia de vida sin miedo y no únicamente en momentos puntuales, sino cuando sea necesario como algo natural y cotidiano, que hablen con sinceridad a los niños de una manera controlada, adecuando la información a la edad y la capacidad de entendimiento del niño (Gómez Hernández, 2006).

La alternativa por la que optan muchos acogedores es ocultar información, pero parece obvio que este ocultamiento está abocado al fracaso, pues, más tarde o más temprano, el niño se enfrentará de una manera descontrolada e inesperada a su dura realidad. En este momento el daño será doble, pues no solo conocerá su historia de vida de una manera muy brusca, sino que se dará cuenta de que las personas más importantes en su vida le han estado engañando muchos años, dañando así los vínculos afectivos (Fuentes y García Bermejo, 2014) y desarrollando sentimientos de desconfianza hacia ellos.

Los niños suelen saber más de su pasado que lo que los acogedores piensan. Poseen imágenes y recuerdos, que en numerosas ocasiones no comparten con los acogedores por varias razones. Una de ellas puede ser que los niños no quieran hablar o preguntar por sus padres para no hacer daño a los acogedores, ya que pueden creer que así les traicionan por un conflicto de lealtades. Otra de las razones puede ser que en alguna ocasión han preguntado y los acogedores no han respondido o han evitado dar respuesta clara a la pregunta, por lo que el niño puede interpretar que es un tema del que los acogedores no quieren hablar, dejando así de preguntar sobre ello. Y la última razón es que la propia naturaleza traumática del pasado del niño le impide o dificulta poner palabras a lo que le sucedió. Independientemente de la razón por la que no se hable del pasado del niño, hace que éste se convierta en un tema tabú en la familia, del que explícita o implícitamente está prohibido hablar. Así, la historia de vida del niño se constituye como un secreto que termina rigiendo la dinámica familiar y establece reglas de 
funcionamiento patógenas (Ausloos, 1998), provocando un clima de homeostasis o estancamiento en el que se impide al acogido elaborar de manera adecuada su historia de vida y, por consiguiente, su identidad. Si el niño no tiene respuesta ante las preguntas que se plantea, irá rellenando sus lagunas con información irreal, muchas veces inventada por el propio niño, por lo que se irá construyendo su pasado sobre una ficción. La consecuencia final podría ser que el desarrollo del niño y su consiguiente construcción de la identidad quedarán dañados si no se actúa para evitarlo. Para que la historia de vida del niño se elabore adecuadamente, los menores puedan poner palabras a su pasado y los acogedores sepan contestar adecuadamente a las preguntas de los niños la intervención socioeducativa puede recurrir a las narrativas.

\section{El USO DE LAS NARRATIVAS PARA LA ELABORACIÓN DE LA HISTORIA DE VIDA EN EL ACOGIMIENTO EN FAMILIA EXTENSA}

Como hemos indicado, las experiencias humanas son discursivas, por lo que recurrimos al uso de las narrativas como estrategias adecuadas para la elaboración de la historia de vida de los niños acogidos. Estas estrategias son verdaderamente importantes para las personas, ya que el uso de la palabra diferencia a los humanos de otras especies, permite que el individuo se integre en la sociedad y alcance un desarrollo maduro, donde es necesario el esfuerzo y la colaboración de otras personas (Ibánez-Martín, 2017), ya que los niños no aprenden a hablar si no hay nadie que les enseñe. Por ello, es importante que el menor acogido, para elaborar su historia de vida, pueda contar con el apoyo de sus cuidadores.

La expresión de sentimientos y pensamientos, tanto por escrito como oralmente, puede tener consecuencias muy positivas para los menores acogidos. Por un lado, pueden poner palabras a sus emociones (Escudero, Abascal y Varela, 2008), lo que conlleva que sean más conscientes de ellas y les resulte más sencillo articular estrategias de autocontrol; por otro lado, les puede ayudar a librarse de una carga, que en numerosas ocasiones es muy pesada. Por ejemplo, elaborar un relato en el que se describa abiertamente su condición de acogido puede ayudar a los menores a desprenderse de sentimientos de inferioridad o de culpabilidad; les concede la oportunidad de expresar lo que sienten al vivir con otros familiares que no son sus padres, sus miedos, inquietudes, etc.; y puede facilitar tanto al menor el comprender sus sentimientos y actitudes, como a las personas que le escuchan el entender el comportamiento del propio niño.

Hay algunos acontecimientos que solo pueden mostrarse a través de las narraciones y, en concreto, de la literatura y las autobiografías, ya que éstas no sólo transmiten una realidad y la muestran, sino que permiten a las personas introducirse dentro de ella e interpretarla. Así la narración se hace propia y puede plasmar realmente lo que es y lo que siente. 


\subsection{Las narrativas para desarrollar la resiliencia en los niños acogidos}

El concepto de resiliencia, en su sentido originario, hace referencia a la capacidad que tienen algunos materiales para recuperar su forma inicial tras haber sufrido una deformación por la aplicación sobre ellos de una fuerza externa. Autores como Barudy (2005, 2006, 2010, 2011) o Cyrulnik (2009, 2010a, 2013a, 2016) han estudiado este término desde al ámbito de las ciencias sociales para referirse a las habilidades y recursos de las personas que posibilitan la superación de circunstancias adversas, lo que puede ser realizado tanto individualmente como en el grupo familiar. Obviamente, en cuanto que medida de protección de la infancia, este concepto resulta muy pertinente en el acogimiento en familia extensa (FuentesPeláez, Balsellst, Fernández, Vaqueros y Amorós, 2016), donde la elaboración de la historia de vida constituye un elemento clave en el desarrollo de la resiliencia.

Barudy y Dantagnan (2010) plantean que existen dos tipos de resiliencias, la primaria y la secundaria. La primaria se desarrolla en niños de entre los 0 y 3 años gracias a los cuidados y buenos tratos que reciben de sus cuidadores. Podría decirse que es la resiliencia más evolutiva y que tienen la mayor parte de los niños. Gracias a ella, los niños pueden socializarse y resolver los problemas de la vida cotidiana. Sin embargo, esta resiliencia primaria puede verse dañada si el menor no cuenta con los cuidados básicos adecuados, sufre malos tratos, negligencia, etc. Si este niño no dispone de otras personas significativas que le traten bien, no desarrollará la resiliencia primaria, mientras que si cuenta con alguna persona que le proporcione amor, aunque no sean los propios padres, podría desarrollar la resiliencia secundaria, que es la capacidad que tienen las personas para salir adelante de manera adecuada a pesar de haber sufrido dolor o traumas en la infancia. Es decir, los menores acogidos en familia extensa debido a un pasado de tratos inadecuados que dio lugar a la medida de protección podrían no haber desarrollado la resiliencia primaria, pero si los acogedores ejercen una parentalidad positiva con ellos, basada en el afecto y en la cobertura de necesidades, podrían desarrollar una resiliencia secundaria.

Siguiendo a Grotberg (2008), para desarrollar la resiliencia es necesario: tener apoyos externos, contar con un adulto de confianza, recibir afecto de otras personas, que las familias sepan adaptarse a las necesidades del niño y que entre los miembros de la familia existan canales de comunicación adecuados. Si trasladamos este planteamiento a los acogimientos en familia extensa, encontramos que los apoyos externos referidos a la incondicionalidad, normas, cobertura de necesidades básicas, etc., pueden proporcionarlos las familias de los menores, así como el afecto y el cariño que recibe el niño simplemente por el hecho de ser familiar directo de los acogedores. La confianza entre el menor y su familia acogedora puede traducirse en la ausencia de mentiras en relación a la historia de vida del niño. Si los acogedores favorecen esta comunicación y no ocultan información al menor sobre su pasado, los acogidos confiarán en sus cuidadores y se podrá desarrollar la resiliencia familiar, pues una comunicación franca es la clave para el desarrollo de la resiliencia (Walsh, 1998). 
Con respecto a la utilización de las narrativas como generadoras de resiliencia, la misma autora afirma que "Tiene especial importancia una coherencia narrativa que ayude a los miembros de la familia a conferir sentido a sus experiencias de crisis y genere colaboración, eficacia y confianza en la superación de los retos que sufre la familia» (Walsh, 1998, 12). Por ello, si la familia acogedora y el profesional ayudan al menor a desarrollar una narración con sentido y real con respecto a su historia de vida, el pasado del menor, aunque sea duro, será entendido y elaborado por éste. Además aumentará la confianza del menor en sus cuidadores, convirtiéndose éstos en verdaderos tutores de resiliencia y les aportará confianza para afrontar otras adversidades a las que tengan que hacer frente. Así mismo, si el profesional que trabaja con el menor y la familia se constituye también como una persona significativa para el núcleo familiar, aumentan las posibilidades de éxito de la intervención socioeducativa (Montserrat y Melendro, 2017).

\subsection{La autobiografía en situaciones de vulnerabilidad}

Las autobiografías tienen la capacidad de promover el conocimiento de uno mismo y del mundo que le rodea, elaborar una narrativa de la propia identidad y dar sentido a acontecimientos vividos (Gil Cantero, 1997), permitiendo pensar en nuestro pasado para entender mejor nuestro presente (Sotos, López Esteban y Sánchez García, 2016). Por ello, son una herramienta narrativa muy eficaz para que los menores acogidos puedan conocer más aspectos de ellos mismos y dotar de sentido a los episodios y situaciones vividas en el pasado, dando así coherencia a sus sentimientos y emociones.

Un ejemplo claro sobre la utilización de las autobiografías en situaciones de vulnerabilidad lo encontramos en el campo de estudio del exilio, y más concretamente en los niños que fueron víctimas de la catástrofe de la guerra. Algunos exiliados en la infancia utilizan en la vida adulta la escritura de sus autobiografías como una manera de reubicar en su mente los acontecimientos que vivieron y ponerles palabras, para lograr así narrar su experiencia y continuar con su vida adulta (Elío, 2002). María Luisa Elío fue víctima con tan solo 9 años del exilio provocado por la Guerra Civil española. A su corta edad tuvo que hacer frente al arresto de su padre, vivió los bombardeos de su ciudad y sufrió el desarraigo de su país. A pesar de haber crecido en México tras su salida de España, donde construyó una familia, su pasado la persiguió durante toda su vida y tuvo una necesidad vital de escribir sobre su historia de vida y regresar 30 años después de la guerra a Pamplona, para poder cerrar sus heridas y darle una explicación a lo que vivió en su infancia. Sin duda, es un caso extremo de violencia infantil, pero que presenta muchas similitudes con algunas de las situaciones vividas por los menores acogidos en familia extensa.

En ambas situaciones los menores pueden sufrir maltratos tanto de forma física como psíquica, se producen rupturas familiares, en las que los niños tienen que abandonar su hogar, su entorno, sus amistades y, sobre todo, a sus padres. 
Además, frecuentemente son los adultos quienes, aunque deberían ser fuente de protección y seguridad, tienen en mayor o menor medida responsabilidad en la situación traumática, lo que incrementa la confusión en los menores dificultando la elaboración del sentido de la experiencia vivida (Barudy y Marquebreucq, 2006), aumentando las posibilidades de que ésta se mantenga como experiencia fallida o se convierta en experiencia imaginaria reactiva.

Los niños que han vivido este tipo de situaciones, sin tener a su lado a una persona que les ayude a entenderlo, pueden crecer sin elaborar su historia de vida y pueden verse atrapados en un pasado que les persigue y que inunda sus pensamientos sin ningún control. Recrean una y otra vez los recuerdos de su pasado, viviéndolos con mucha intensidad y configurándose como una realidad paralela que algunas veces es incluso peor que la realidad misma (Jato, 2016). Estos recuerdos pueden ser incoherentes, descontextualizados y, en muchas ocasiones, perturban el bienestar de la persona que los sufre. Dice Elío (2002, 20): «Lo recuerdo todo, lo recuerdo como si el tiempo lo hubiera roto y las piezas no encajaran ya unas con otras».

Boris Cyrulnik, neurólogo, psiquiatra y psicoanalista francés, es otro ejemplo de niño exiliado que utiliza la narrativa para contar su historia de vida y a la vez ayudarse a sí mismo a entenderla. Describe cómo ya siendo adulto seguía teniendo recuerdos inconexos e incoherentes sobre su pasado y que, mediante el contacto con las personas que le cuidaron de niño, ha sido capaz de elaborar su historia de vida dotándola de una narrativa comprensible y coherente. Asimismo, el propio autor pone el énfasis en la importancia de que este proceso de elaboración narrativa de la historia de vida sea una tarea compartida, en la que el niño o el adulto se apoye en otras personas de referencia que le ayuden en el proceso de reconstrucción y significación de los recuerdos (Cyrulnik, 2010b).

Si los profesionales o la familia acogedora no ayudan a los niños acogidos cuando son pequeños a darle sentido y coherencia a su historia vital, puede producirse esta situación en la que la realidad construida por el adulto que perdió su infancia no se asemeje a su realidad pasada, que con el paso del tiempo sea una imaginación, una fantasía. Si se deja que los niños vivan de sus recuerdos distorsionados se puede producir en ellos un estancamiento psicológico, que desencadene una vivencia permanente de su pasado, impida vivir el presente y mirar hacia el futuro, como le sucedió a María Luisa Elío.

En los acogimientos en familia extensa, sin embargo, la realización de autobiografías debe afrontarse desde una perspectiva diferente a la de las autobiografías de infancia que consisten en la narración de un adulto de diferentes episodios de su infancia, en las que escribe sus recuerdos de la niñez y selecciona la información que más le interesa contar (Baena, 2000), concediéndose incluso ciertas licencias a la imaginación o la libre interpretación del autor. En nuestro caso, se trata de una autobiografía de infancia escrita por los propios menores, donde más que la selección de determinados momentos concentrados en el tiempo, prima la coherencia y la continuidad narrativa, la imaginación conviene que esté impregnada de realismo, 
TANIA GARCÍA BERMEJO

y la historia sea contada en un lenguaje con menor carga retórica que la haga más accesible al desarrollo psicoemocional del niño.

\subsection{El libro de vida}

El libro de vida es una estrategia socioeducativa de gran valor en el trabajo de la historia de vida con menores acogidos (Jiménez Morago, Martínez Cabeza y Mata Fernández, 2010). Se trata de un documento en forma de libro en el que el menor puede ir recogiendo información variada sobre acontecimientos significativos que han tenido lugar a lo largo de su vida. A diferencia de la autobiografía, el libro de vida puede incluir información no sólo textual, sino también imágenes y dibujos, e incluso, en algunas propuestas recientes, puede elaborarse en forma virtual e incluir audios y videos (García Bermejo y Fuentes, 2013). En el acogimiento en familia extensa es recomendable que el niño encuentre espacio para escribir o representar con imágenes aspectos importantes que, a pesar de la diversidad de situaciones existentes, pueden dividirse en tres momentos diferentes: un espacio para el pasado, donde tengan cabida, primeramente, sus padres biológicos, pero también los acogedores, prestando atención al proceso por el que se realizó el acogimiento familiar; otro para su presente, donde el papel preponderante será para la familia acogedora, pero donde podrán aparecer también los progenitores, especialmente si tienen aún contacto con el menor; y, por último, otro lugar para hablar sobre su futuro, donde el niño proyecte sus deseos y aspiraciones a largo plazo. De esta forma, el libro de vida supone una oportunidad abierta para que los niños recojan sus recuerdos más significativos, expresen sus miedos y anhelos, así como aquellos otros aspectos que el menor desee destacar. Se trata de una invitación a escribir libremente sobre uno mismo, recoger imágenes que pueden expresar mejor que las propias palabras, etc.

Para su elaboración es positivo que cuente con la ayuda de su familia, de los acogedores e incluso de sus padres biológicos si mantiene relación con ellos. Por ello, es un espacio propicio para fomentar el diálogo entre el niño y sus cuidadores, así como un momento idóneo para que el menor pueda hacer preguntas y obtener respuestas aclaratorias y concisas sobre las lagunas que puede tener sobre su pasado o sobre los hechos que no entiende o no puede ponerles palabras, rompiéndose de esta manera el posible tabú creado sobre su historia de vida. Por lo tanto, no sólo se trata de que el niño pueda ir rellenando su libro de vida, sino de crear un espacio propicio entre el niño y sus cuidadores para que éste pueda preguntarles en cualquier momento lo que necesite.

Otro recurso complementario al libro de vida que se puede utilizar para la elaboración de la historia de vida es un álbum de fotografías en el que el niño pueda ir recopilando imágenes de él cuando era pequeño, de sus padres biológicos, de su familia acogedora, etc. Cuando los acogidos son pequeños se les puede ir mostrando este álbum fotográfico como si fuera un cuento, explicándoles su historia de vida de una manera sencilla, para que el menor pueda identificar a sus familiares y 
tener una explicación de quiénes forman parte de su vida. El niño puede ir viendo y comprobando que sus padres le querían y con los que pasó buenos momentos, pero por circunstancias de la vida ya no puede vivir con ellos y ahora lo hace con otros familiares que le cuidan de una manera adecuada.

\subsection{El uso de la literatura}

El poder formativo de la literatura es innegable. Siguiendo a López Quintás (1994), quien afirma que el lector de una obra literaria la recrea en función de sus experiencias nucleares, no cabe duda de que es una herramienta fundamental para la elaboración de la historia de vida en acogimientos familiares.

A través de la literatura, los menores acogidos pueden revivir situaciones pasadas y comenzar a entender los que les sucedió. Del mismo modo, y especialmente cuando los niños son pequeños, se les puede ir introduciendo en su historia de vida a través de la lectura de algún cuento en el que el protagonista sea un niño o una niña que tenga una realidad simular a la suya. Son muchos y ampliamente conocidos e integrados en la cultura popular los ejemplos que pueden encontrarse en este sentido en las obras de literatura infantil, como Las aventuras de Pinocho, de Carlo Collodi, donde el juguete de madera que cobrará vida reside con el carpintero Geppetto que podría ser su abuelo, o El Mago de Oz, de Lyman Frank Baum, cuya protagonista adolescente vive con sus tíos.

Cuando el niño lea o escuche el cuento es probable que se identifique con el personaje principal, pues reconocerá los elementos que ambos tienen en común, lo que le puede llevar a hacerse preguntas sobre él mismo, sus sentimientos (Carr, 2005), su pasado y su futuro (García Amilburu, 2005). Este proceso, que en un apartado anterior describimos como efecto espejo, facilitará que el niño pueda poner sus dudas y preguntas en boca del personaje de ficción, preguntar a través de él, pues es más sencillo para un niño preguntar en tercera persona que en primera. Es decir, preguntará los motivos por los que la protagonista de El Mago de $\mathrm{Oz}$ reside con sus tíos y no con sus padres, pudiendo trasladar la respuesta de los acogedores a su propia situación. Del mismo modo, para los familiares también puede ser más fácil contar al niño las causas por las que el personaje de ficción reside con sus allegados que explicar al propio niño las causas de su acogimiento familiar.

Este proceso no sólo sirve para rellenar las lagunas que tienen los niños y que no se atreven a preguntar directamente a sus cuidadores, sino también para normalizar su situación. Pues no son ellos solos los niños raros que residen con sus abuelos o tíos, sino que, por ejemplo, un superhéroe admirado por los niños de su edad como Spiderman también lo hace. Además, podría servir para conformar la identidad social de los niños, al ser conscientes de que forman parte de un grupo que tiene características compartidas que le diferencian de otros grupos sociales (Tajfel, 1978). 


\section{CONClusiones}

El desarrollo del Estado del Bienestar en las sociedades occidentales ha posibilitado el acceso de gran parte de la población a recursos muy variados que no sólo facilitan la subsistencia de los individuos, sino también el desarrollo de una vida digna. La sanidad, la educación o los servicios sociales son algunos de sus principales pilares que, tras unos años de extensión y consolidación, afrontan ahora el reto de mejorar la calidad del servicio que ofrecen a los ciudadanos, donde la especialización de las actuaciones constituye uno de los criterios clave para la intervención socioeducativa (Pérez Serrano, Poza y Fernández García, 2016). Para dar respuesta a esta necesidad de especialización, desde hace algunos años varias comunidades autónomas españolas vienen desarrollando diversos programas socioeducativos, donde profesionales con formación pedagógica como los educadores sociales o los psicopedagogos tienen una presencia relevante, y cuyo fin es realizar un apoyo sistematizado a las familias acogedoras y a los niños acogidos. Ello supuso el reconocimiento, por un lado, de esta modalidad de acogimiento dentro del sistema de protección de menores y, por otro, de las necesidades específicas de estas familias, recibiendo la atención socioeducativa especializada que hasta ese momento no recibían por parte de los Servicios Sociales Generales. A pesar de esta importante mejora, a día de hoy es posible y necesario continuar desarrollando actuaciones socioeducativas que mejoren la calidad de vida de los acogidos en familia extensa, pues son las propias familias quienes demandan mayor atención familiar (Jiménez Morago y Palacios, 2008).

Resulta imprescindible que estas actuaciones se encuentren sólidamente fundamentadas, para lo cual, la teoría de la educación está llamada a desempeñar un papel insustituible, como referencia de las prácticas socioeducativas en diversos contextos. En este sentido, este artículo se ha centrado en la fundamentación y presentación de algunas propuestas socioeducativas que permiten trabajar la elaboración de la historia de vida y la formación de una identidad madura con menores acogidos en familia extensa. Para ello, hemos expuesto el proceso por el cual se elabora la identidad de estos niños partiendo de los conceptos de experiencia fallida de Alphen (1999), quien entiende que la experiencia es discursiva $y$, sin palabras que narren lo vivido, dicha experiencia se convierte en trauma; la experiencia imaginaria reactiva, en la cual sí existe narración sobre lo sucedido, pero ésta no es acorde con la realidad y resulta muy negativa para la formación de la identidad del menor; y el estadio del espejo de Lacan (2009), que nos permite asemejarlo con el conocimiento de la historia de vida del menor acogido y la importancia que tienen los acogedores en ello. A continuación, hemos realizado un seguimiento de esta cuestión en la legislación y hemos expuesto algunas razones prácticas para el conocimiento de la realidad en la historia de vida, pues, aunque esto puede escocer, es como un desinfectante que cura. Y, por último, proponemos la utilización de las narrativas y, más concretamente, las autobiografías, el libro de vida y la literatura, como estrategias socioeducativas para contribuir al desarrollo de la identidad del niño y fomentar su resiliencia. 
Terminemos con unas palabras de Cyrulnik, quien, tras usar la narración y, concretamente, la autobiografía para dar sentido a su propio pasado, recoge en pocas líneas su específica y valiosa contribución a la reconstrucción de la historia de vida en situaciones de vulnerabilidad, como es el caso del acogimiento en familia extensa: "Lo que reúne y coordina los pedazos verdaderos de mi quimera es el sentido que hoy atribuyo a los hechos pasados. La narración permite ese trabajo de armonización de mis recuerdos y orienta el galope de mi quimera. Sin ella, cada pedazo de verdad iría en su propia dirección y nada tendría sentido. No podría saber quién soy, lo que me gusta y a lo que aspiro» (Cyrulnik, 2013b, 34).

\section{REFERENCIAS BIBLIOGRÁFICAS}

Aguirre, R. (1998) La verdad, la justicia y el perdón ante la victimación. Eguzkilore. Cuaderno del Instituto Vasco de Criminología, 12, 77-88.

Alphen, E. (1999) Symtoms of Discursivity: Experience, Memory, and Trauma, en BAL, M.; Crewe, J. V. y Spitzer, L. (eds.) Acts of Memory. Cultural Recall in the Present. Hanover, Dartmouth College, 24-38.

Ausloos, G. (1998) Las capacidades de la familia. Barcelona, Herder.

BAEnA, R. (2000) Childhoods: La autobiografía de infancia como subgénero narrativo en auge. Rilce, 16 (3), 479-489.

Balsells, M. A.; Fuentes-Peláez, N.; Mateo Gomà, M.; Mateos Inchaurrondo, A. y Violant Hoz, V. (2010) Innovación socioeducativa para el apoyo de adolescentes en situación de acogimiento familiar. Educar, 45, 133-148.

Barudy, J. y Dantagnan, M. (2005) Los buenos tratos a la infancia. Parentalidad, apego y resiliencia. Barcelona, Gedisa.

Barudy, J. y Dantagnan, M. (2010) Los desafíos invisibles de ser madre o padre. Manual de evaluación de las competencias y la resiliencia parental. Barcelona, Gedisa.

BARUdy, J. y DANTANGNAN, M. (2011) La fiesta mágica y realista de la resiliencia infantil: manual y técnicas terapéuticas para apoyar y promover la resiliencia de los niños, niñas y adolescentes. Barcelona, Gedisa.

BARUdy, J. y MARQuebreucQ, A. P. (2006) Hijas e hijos de madres resilientes. Traumas infantiles en situaciones extremas: violencia de género, guerra, genocidio, persecución y exilio. Barcelona, Gedisa.

Bernal Guerrero, A. (2011) Postmodernización y educación. Notas para el debate de una narrativa pedagógica centrada en la identidad. Educación XX1, 14 (2), 285-302.

Bernal Guerrero, A. y König Bustamante, K. L. (2017) Percepciones de adolescentes sobre la educación según la identidad personal. Revista Española de Pedagogía, 267, 181-198.

BERNEDO, I. M. y FueNTES, M. J. (2010) Necesidades de apoyo y satisfacción en los acogimientos con familia extensa. Anales de Psicología, 26 (1), enero, 95-103.

Borges del Rosal, A.; Rodríguez Naveiras, E. y Hernández Jorge, C. M. (2013) El acogimiento familiar en la provincia de Santa Cruz de Tenerife: estudio descriptivo. Intervención psicoeducativa en la desadaptación social: IPSE-ds, 1, 11-20.

CARO, M. C. (2013) El uso de la autobiografía de infancia como recurso para la investigación en educación. Revista Española de Pedagogía, 256, 509-523.

CARR, D. (2005) On the contribution of literature and the arts to the educational cultivation of moral virtue, feeling and emotion. Journal of Moral Education, 34 (2), 137-151. 
Coleman, J. y Hendry, L. (2003) Psicología de la adolescencia. Madrid, Morata.

Convención de 20 de noviembre de 1989 sobre los derechos del niño. Consultado el 12 de julio de 2017. http://www.unicef.org/argentina/spanish/7.-Convencionsobrelosderechos.pdf.

CyRulnik, B. (2003) El murmullo de los fantasmas: volver a la vida después de un trauma. Barcelona, Gedisa.

Cyrulnik, B. (2009) Autobiografía de un espantapájaros: testimonios de resiliencia: el retorno a la vida. Barcelona, Gedisa.

Cyrulnik, B. (2010a) El amor que nos cura. Barcelona, Gedisa.

Cyrulnik, B. (2010b) Me acuerdo: el exilio de la infancia. Barcelona, Gedisa.

Cyrulnik, B. (2013a) Los patitos feos. Barcelona, Gedisa.

Cyrulnik, B. (2013b) Sálvate, la vida te espera. Barcelona, Debate.

CyRulnik, B. y ANAUT, M. (2016) ¿Por qué la resiliencia?: lo que nos permite reanudar la vida. Barcelona, Gedisa.

Declaración de los Derechos del Niño (1959). Consultado el 12 de julio de 2017. http://www. humanium.org/es/declaracion-de-los-derechos-del-nino-texto-completo/.

Del Valle, J. F.; Bravo, A. y López, M. (2009) El acogimiento familiar en España: Implantación y retos actuales. Papeles del Psicólogo, 30 (1), 33-41.

Del Valle, J. López, M.; Montserrat, C. y Bravo, A. (2008) El Acogimiento familiar en España. Una evaluación de resultados. Oviedo, Ministerios de Trabajo y Asuntos Sociales.

Del Valle, J. F. y Bravo, A. (2003) Situación actual del acogimiento familiar de menores en España. Universidad de Oviedo, Dirección General de Acción Social, del Menor y la Familia, del Ministerio de Trabajo y Asuntos Sociales. Consultado el 12 de mayo de 2017. http://www.observatoriodelainfancia.msps.es/documentos/Informe_acogida_ familiar.pdf.

Elío, M. L. (2002) Tiempo de llorar y otros relatos. Madrid, Turner.

Escudero, V.; ABASCal, A. y VArela, N. (2008) Escaleras y torreones terapéuticos: directrices y técnicas básicas para el trabajo con niños en terapia familiar. Cuadernos de Psiquiatría Comunitaria, 8 (2), 207-223.

Fuentes, J. L. y García Bermejo, T. (2014) Formación de la identidad y relación educativa en contextos de dificultad social: el acogimiento en familia extensa. Revista Española de Pedagogía, 257, 143-158.

Fuentes-Peláez, N.; Balsellst, M. A.; Fernández, J.; Vaqueros, E. y Amorós, P. (2016) The social support in kinship foster care: a way to enhance resilience. Child and Family Social Work, 21, 581-590.

García Amilburu, M. (2005) Literatura, virtudes y educación moral. Bordón. Revista de Pedagogia, 54 (5), 609-622.

García Bermejo, T. y Fuentes, J. L. (2013) Creando nuevos caminos: un espacio virtual terapéutico para la intervención socioeducativa con adolescentes acogidos, en VIII Congreso Nacional de Terapia Familiar: Nuevas formas de conexión: terapia familiar y nuevas tecnologias. Universidad Pontificia Comillas.

Gil CANTERo, F. (1997) Educación y narrativa: la práctica de la autobiografía en la educación. Teoría de la Educación, 9, 115-136.

Gómez Hernández, F. J. (2006) Los niños necesitan saber. Reflexiones en torno a la problemática y la importancia de comunicar o clarificar a los niños que se encuentran 
acogidos por su familia extensa su situación y/o su historia personal y familiar. Información Psicológica, 88, 45-54.

GonZALo MARRodÁn, J. L. (2010) La relación terapéutica y el trabajo de reconstrucción de la historia de vida en el tratamiento psicoterapéutico de los niños crónicamente traumatizados. Cuadernos de Psiquiatría y Psicoterapia del Niño y del Adolescente, 49, 187-204.

Grotberg, E. (2008) ¿Qué entendemos por resiliencia? ¿Cómo promoverla? ¿Cómo utilizarla?, en Grotberg, E. (comp.) La resiliencia en el mundo de hoy. Cómo superar las adversidades. Barcelona, Gedisa, 17-58.

IbáÑez-Martín, J. A. (2017) Horizontes para los educadores. Las profesiones educativas y la promoción de la plenitud humana. Madrid, Dykinson.

Jato, M. (2016) María Luisa Elío: experiencia, trauma y literatura, en GonZÁlez-Allende, I. (ed.) El exilio vasco: estudios en homenaje al profesor José Ángel Ascunce Arrieta. Bilbao, Universidad de Deusto, 233-256.

Jiménez, J. M.; MartíneZ, R.; MuÑoz, A. y León, E. (2013) Comunicación sobre el acogimiento y funcionamiento familiar en familias extensas acogedoras. Cultura y Educación, 25 (2), 229-240.

Jiménez Morago, J. M.; Martínez Cabeza, R. y Mata Fernández, E. (2010) Guía para trabajar la historia de vida con niños y niñas. Acogimiento familiar y residencial. Junta de Andalucía, Consejería para la Igualdad y Bienestar Social.

Jiménez Morago, J. M.; Martínez Cabeza, R. y Mata Fernández, E. (2013) Comunicación, orígenes e identidad en el acogimiento familiar y residencial: el programa «Viaje a mi historia». Apuntes de Psicología, 31 (3), 307-315.

Jiménez Morago, J. M. y Palacios, J. (2008) El acogimiento familiar en Andalucía. Procesos familiares, perfiles personales. Granada, Junta de Andalucía.

LACAN, J. (2009) El estadio del espejo como formador de la función del yo [je] tal como se nos revela en la experiencia psicoanalítica, en Lacan, J. Escritos 1. México, Siglo XXI, 99-105.

Ley Orgánica 1/1996, de 15 de enero, de Protección Jurídica del Menor, de modificación parcial del Código Civil y de la Ley de Enjuiciamiento Civil.

Ley Orgánica 8/2015, de 22 de julio, de modificación del sistema de protección a la infancia y a la adolescencia.

LóPez Quintás, A. (1994) Cómo adquirir formación ética a través de la literatura. Revista Española de Pedagogía, 198, 313-343.

LÓPEZ-SOLER, C. (2008) Las reacciones postraumáticas en la infancia y adolescencia maltratada: el trauma complejo. Revista de Psicopatología y Psicología Clínica, 13 (3), 159-174.

Molero, R. J.; Moral, M. a J.; Albiñana, P.; Sabater, Y. y Sospedra, R. (2007) Situación de los acogimientos en familia extensa en la ciudad de Valencia. Anales de Psicología, 23 (2), 193-200.

Montserrat, C. (2006) Acogimiento en familia extensa: un estudio desde la perspectiva de los acogedores, de los niños y niñas acogidos y de los profesionales que intervienen. Intervención Psicosocial, 15 (2), 203-221.

MontSERrat, C. (2008) Niños, niñas y adolescentes acogidos por sus familiares: ¿qué sabemos? ¿qué conocemos? Barcelona, Generalitat de Catalunya.

Montserrat, C. y Melendro, M. (2017) ¿Qué habilidades y competencias se valoran de los profesionales que trabajan con adolescencia en riesgo de exclusión social? Análisis desde la acción socioeducativa. Educación XX1, 20 (2), 113-135. 
MúgicA, J. (2010) Claves y recursos narrativos para el abordaje de la condición adoptiva de niños, niñas y adolescentes, en Loizaga, F. Adopción Hoy: Nuevos desafíos, nuevas estrategias. Bilbao, Mensajero, 399-428.

Nodings, N. (2009) La educación moral. Propuesta alternativa para la educación del carácter. Buenos Aires, Amorrortu.

Palacios, J. (2014) Valoración de idoneidad para el acogimiento familiar. Granada, Junta de Andalucía. Consejería de Igualdad, Salud y Políticas Sociales.

Pérez Serrano, G.; Poza, F. y Fernández García, A. (2016) Criterios de calidad para la intervención con jóvenes en dificultad social. Revista Española de Pedagogía, 263, 51-69.

Plan Estratégico Nacional de la Infancia y Adolescencia 2013-2016. Consultado el 12 de julio de 2017. https://www.msssi.gob.es/ssi/familiasInfancia/Infancia/pdf/II_PLAN_ESTRATEGICO_INFANCIA.pdf.

Platón (1990) La República, en Obras Completas. Madrid, Aguilar, 655-844.

Pinazo, S. y Ferrero, C. (2003) Impacto psicosocial del acogimiento familiar en familia extensa: el caso de las abuelas y los abuelos acogedores. Revista Multidisciplinar de Gerontología, 13 (2), 89-101.

SáncheZ Moro, C. y colaboradores (2000) El acogimiento familiar de los menores hijos de padres toxicómanos. Barcelona, Intress.

Sotos, M. A.; López Esteban, C. y SÁnchez García, A. (2016) La perspectiva biográfica. El proceso de construcción del saber pedagógico. Teoría de la Educación, 28 (2), 249-265.

TAjFeL, H. (1978) Differentiation between social groups: Studies in the social psychology of intergroups relations. Londres, Academic Press.

TAjFEL, H. (1984) Grupos humanos y categorías sociales. Barcelona, Herder.

Vis, S. A.; Handegård, B. H.; Holtan, A.; Fossum, S. y Thørnblad, R. (2016) Social functioning and mental health among children who have been living in kinship and nonkinship foster care: results from an 8-year follow-up with a Norwegian sample. Child and Family Social Work, 21 (4), 557-567.

Walsh, F. (1998) El concepto de resiliencia familiar: crisis y desafío. Sistemas Familiares, marzo, 11-32. 
